\title{
Case report of severe myocarditis in an immunocompromised child with Respiratory Syncytial Virus infection
}

\author{
Hiroki Miura ${ }^{1}$, Fumihiko Hattori', Hidetoshi Uchida', Tadayoshi Hata ${ }^{2}, K^{1}$ Kazuko Kudo ${ }^{1}$, Masatoki Sato ${ }^{3}$ \\ and Tetsushi Yoshikawa ${ }^{1 *}$
}

\begin{abstract}
Background: Respiratory syncytial virus (RSV) infection is common and may be severe among patients with preexisting cardiac anomalies, but direct involvement of myocardial damage is not common in those patients. Additionally, myocardial involvement has been rarely described among immune compromised children.

Case presentation: A 4-year-old girl with acute lymphoblastic leukemia who received maintenance chemotherapy in an outpatient clinic developed systemic inflammatory response syndrome. RSV infection was confirmed by a positive rapid antigen test and serological assay. Subsequently, she was diagnosed with severe myocarditis caused by RSV infection, which was diagnosed by abnormal findings of cardiac echography and ECG and elevated biomarkers for myocardial damage. Then, she was treated in the intensive care unit for 13 days. High amounts of RSV type B RNA was detected in tracheal aspirates and serum sample.
\end{abstract}

Conclusion: This case report emphasizes that RSV infection may be associated with myocarditis in immunocompromised children receiving maintenance chemotherapy.

Keywords: RSV, Myocarditis, Leukemia, Maintenance treatment, Real-time RT-PCR

\section{Background}

Respiratory syncytial virus (RSV) is one of the most important viral causes of lower respiratory tract infection (LRTI) in infancy and childhood. It is well known that premature infants, infants with cardiac diseases, and immunocompromised patients, including leukemic children, are at high risk for more severe and complicated RSV infection. Although severe LRTI caused by RSV infection is associated with high morbidity in patients with acute lymphoblastic leukemia [1], no RSV myocarditis case has been reported in such patients. This report describes an immunocompromised child with severe myocarditis caused by RSV infection and detection of high amounts of viral genome in not only tracheal tube aspirates but also serum sample based on real-time revers transcription polymerase chain reaction (RT-PCR).

\footnotetext{
* Correspondence: tetsushi@fujita-hu.ac.jp

${ }^{1}$ Department of Pediatrics, Fujita Health University School of Medicine, 1-98,

Dengakugakubo, Kutsukake-cho, Toyoake, Aichi 470-1192, Japan

Full list of author information is available at the end of the article
}

\section{Case presentation}

A 4-year-old Japanese girl with B-cell acute lymphoblastic leukemia (ALL) presented to the emergency room with febrile convulsion. The age of disease onset was 3 years and the patient received maintenance chemotherapy in our outpatient clinic. Clinical course of patient is shown in Fig. 1. The patient had a high fever $\left(40.1 \mathrm{C}^{\circ}\right)$, tachypnea (respiratory rate $38 / \mathrm{min}$ ), and tachycardia (pulse rate 180/min). She was diagnosed with febrile neutropenia and systemic inflammatory response syndrome (SIRS) based on her neutrophil count, which was $322 / \mu \mathrm{L}$, as well as remarkably elevated inflammatory responses (CRP: $2.2 \mathrm{mg} / \mathrm{dl}$; procalicitonin: $67.8 \mathrm{ng} / \mathrm{mL}$ ). Chest X-ray revealed mild perihilar infiltration with normal cardiothoracic ratio (51.6\%), and chest computed tomographic scanning showed bilateral consolidation and pleural effusion. Within two hours after admission, the patient's respiratory condition continued to deteriorate despite oxygen supplementation while lactate levels increased to $62.6 \mathrm{mg} / \mathrm{dL}$. The patient was transferred to 


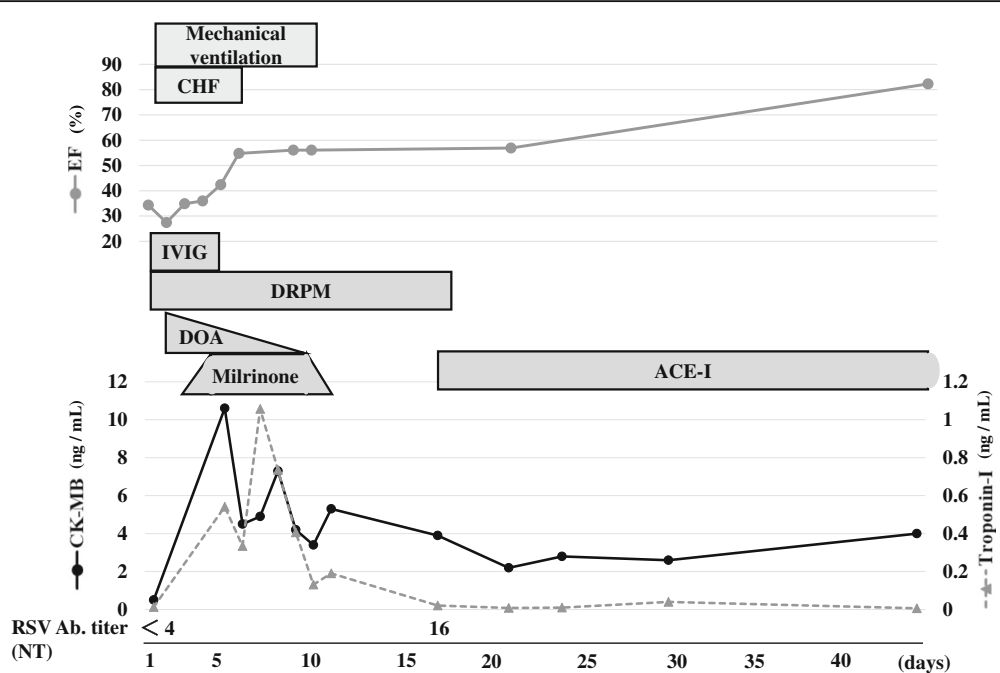

Fig. 1 Clinical course of the patient. Kinetics for the ejection fraction and biomarkers of myocardial damage. Myocardial function and myocardial damage were gradually recovered in the acute phase using intensive treatment. CHF: continuous hemofiltration; EF: ejection fraction; CPK: creatine kinase; MB: muscle and brain; ACE: angiotensin converting enzyme inhibitor

the intensive care unit for mechanical ventilation; however, her systolic blood pressure decreased gradually from 116 to $40 \mathrm{mmHg}$ despite hydration and blood transfusion for volume expansion. Therefore, catecholamine administration, intravenous immunoglobulin, and continuous venovenous hemofiltration were initiated. As we suspected myocardial dysfunction, cardiac ultrasound was performed and showed depressed left ventricular function with an ejection fraction of $27 \%$, as well as a left ventricular Tei index of 0.62 indicating global systolic and diastolic ventricular function, mitral regurgitation, and tricuspid regurgitation. An electrocardiogram showed ST-T wave change in V4-6. Furthermore, a marked increase in myocardial markers was noted, including Troponin-I $0.541 \mathrm{ng} / \mathrm{mL}$ (normal 0-0.04 ng/mL), myoglobin $91.2 \mathrm{ng} /$ $\mathrm{mL}$ (normal 12.8-66.1 ng/mL), and CK-MB $10.6 \mathrm{ng} / \mathrm{mL}$ (0.9-5.9 ng/mL).

Two days after admission to the hospital, her systolic blood pressure improved to $120 \mathrm{mmHg}$ and inotropic support was gradually reduced and stopped by day 9 . In addition to the administration of milrinone for 11 days, continuous hemofiltration was carried out for 6 days to treat the heart failure. Subsequently, left ventricular function gradually improved, and myocardial markers returned to normal levels 17 days after admission to the hospital. Finally, she was discharged from the intensive care unit on day 13.

Three separate blood cultures were negative. Additionally, the patient tested negative for influenza virus, human-metapneumovirus, adenovirus, and Group $A$ streptococcus using rapid antigen tests; however, RSV antigens were detected in a nasal swab at the time of hospital admission. Moreover, seroconversion of RSV antibody titers $(<4$ and 16$)$ was confirmed using a neutralizing antibody test (SRL Inc., Tokyo, Japan). In order to elucidate the pathophysiology of RSV infection, serially collected tracheal tube aspirates and serum samples were examined using real-time RT-PCR [2]. Real-time RT-PCR analysis detected high amounts of RSV type $\mathrm{B}$ RNA in the tracheal aspirates on day 2 $\left(1.6 \times 10^{9}\right.$ copies $\left./ \mathrm{ml}\right)$ and day $5\left(1.4 \times 10^{8}\right.$ copies $\left./ \mathrm{ml}\right)$ after the onset of the disease. Interestingly, viral RNA was also detected in the serum sample obtained on day 1 of the illness $\left(3.2 \times 10^{4}\right.$ copies $\left./ \mathrm{ml}\right)$, but it had decreased to undetectable levels in serum samples collected on days 5 and 8 .

In order to examine the pathophysiology of this severe cardiac complication caused by RSV infection, various cytokines and chemokines were measured in serially collected serum samples using the Cytometric Bead Array system (Table 1). Serum samples were serially collected before the onset of the RSV infection and on days 1, 5, 7, and 14 after illness onset. As shown in Table 1, IL-6, IL-10, IL-8, IFN- $\gamma$, MCP-1, and IP-10 were markedly elevated at the time of disease onset. The levels of these biomarkers returned to normal by 14 days after illness onset.

\section{Discussion and conclusions}

RSV infection in high risk patients, including patients with hematological malignancies, is associated with increased morbidity and mortality. Lymphopenia (lymphocyte counts of $<100 / \mathrm{mm}^{3}$ ) and young age (less than 2 years of age) are predictors of RSV-related LRTI in immunocompromised children [3]. Maintenance treatment is considered to be safer than induction 
Table 1 Kinetics of cytokines and chemokines level in serially collected serum samples

\begin{tabular}{llllll}
\hline Day & Pre & 1 & 5 & 14 & 17 \\
\hline IL-2 $(\mathrm{pg} / \mathrm{mL})$ & 0.0 & 0.0 & 0.0 & 0.0 & 0.0 \\
IL-4 $(\mathrm{pg} / \mathrm{mL})$ & 0.0 & 0.0 & 0.0 & 0.0 & 0.0 \\
IL-6 $(\mathrm{pg} / \mathrm{mL})$ & 0.0 & $17,599.1$ & 92.7 & 0.0 & 0.0 \\
IL-10 $(\mathrm{pg} / \mathrm{mL})$ & 0.0 & 150.6 & 1.7 & 0.0 & 0.0 \\
TNF-a $(\mathrm{pg} / \mathrm{mL})$ & 0.0 & 0.0 & 0.0 & 0.0 & 0.0 \\
IFN- $(\mathrm{pg} / \mathrm{mL})$ & 0.0 & 16.2 & 64.6 & 0.0 & 0.0 \\
IL-8 $(\mathrm{pg} / \mathrm{mL})$ & 0.0 & 5376.5 & 731.4 & 26.9 & 20.8 \\
RANTES $(\mathrm{pg} / \mathrm{mL})$ & $10,878.2$ & $12,011.7$ & 6193.2 & $17,193.4$ & $20,705.5$ \\
MIG $(\mathrm{pg} / \mathrm{mL})$ & 57.2 & 141.32 & 221.7 & 192.1 & 114.5 \\
MCP-1 $(\mathrm{pg} / \mathrm{mL})$ & 238.1 & 9009.0 & 667.4 & 231.0 & 314.2 \\
IP-10 $(\mathrm{pg} / \mathrm{mL})$ & 0.0 & 1104.5 & 2739.1 & 404.3 & 303.0
\end{tabular}

IL interleukin, TNF tumor necrosis factor, IFN interferon, RANTES regulated on activation, normal T cell expressed and secreted, MIG monokine induced by interferon $\mathrm{g}, M C P$ monocyte chemoattractant protein, IP interferon g-inducible protein

treatment because it is associated with lower levels of immunosuppression. Meanwhile, maintenance treatment carried out in outpatient clinics appears to increase the risk for community acquired RSV infection. Recently, Chu et al. [4] reported that 15/54 (28\%) immunocompromised children with RSV infection who were treated in outpatient clinics were later hospitalized due to LRTI. Although RSV-related myocarditis has been demonstrated in healthy children [5-9], to the best of our knowledge, this is the first myocarditis case in association with RSV infection in an immunocompromised patient. Thus, in addition to the LRTI, RSV infection may cause myocarditis in immunocompromised children during maintenance chemotherapy in an outpatient clinic setting.

It is important to note, high amounts of RSV RNA were detected in not only the tracheal aspirates but also the serum sample obtained on day 1 of the illness. A previous study found no association between viral load, including RSV, and disease severity in bronchoalveolar lavage samples collected from hematological stem cell transplant recipients [10]. However, the detection of viral RNA in serum samples was significantly associated with patient mortality [10]. Thus, the detection of RSV RNA in serum samples may serve as a useful prognostic marker in patients with severe RSV infection. Furthermre, in the present case, biopsy of the heart tissue was not performed and thus demonstration of RSV in tissue sample was not possible. This procedure is not routinely performed in children. However, the presence of serum RSV RNA in our patient suggesting systemic viral infection may support the notion of direct invasion of RSV into myocardial tissues as suggested by previous study [6].
It has been suggested that viral invasion of the myocardium or endothelial cells and host immune responses may play important roles in the pathogenesis of viral myocarditis. Several cytokines and chemokines were clearly elevated in our patient during the acute phase of the disease, suggesting that host immune responses may contribute to the pathogenesis of RSV-related myocarditis. It has been suggested that Th1 immune responses initiated by INF- $\gamma[11,12]$ and Th1 chemokines (IP-10) [13] may play important roles in the pathogenesis of viral myocarditis. Additionally, in a murine model, MCP-1 was required for the invasion of monocytes/macrophages into the myocardium [14]. Our present findings of elevated cytokines and chemokines are consistent with the previous studies [11-14]. A large number of cases is necessary to elucidate the pathogenesis of myocarditis caused by RSV infection, indeed, this may be difficult to achieve because the incidence of this complication is extremely low. Therefore, in addition to human data, an animal model should improve our understanding of the precise pathological mechanisms of RSV-related myocarditis.

In conclusion, herein, we reported on a 4-year-old Japanese girl with ALL who suffered from severe myocarditis associated with RSV infection during maintenance treatment. RSV type B RNA was detected in both tracheal aspirates and serum samples during the acute phase of the disease. This case report emphasizes that in addition to lower respiratory tract infections, RSV infection may cause myocarditis in immunocompromised children receiving maintenance chemotherapy.

\section{Abbreviations}

ALL: Acute lymphoblastic leukemia; CK: Creatine kinase; CRP: C-Reactive Protein; ECG: Electrocardiogram; IFN: Interleukin; IL: Interleukin; IP: Interferon g-inducible protein; LRTI: Lower respiratory tract infection; MB: Muscle and brain; MCP: Monocyte chemoattractant protein; RNA: Ribonucleic acid; RSV: Respiratory syncytial virus; RT-PCR: Real-time revers transcription polymerase chain reaction

\section{Acknowledgements}

Authors thank Ms. Akiko Yoshikawa, Ms. Chieko Mori, and Ms. Yoko Osakabe of Fujita Health University School of Medicine, Toyoake, Japan who helped with collection and processing samples.

\section{Funding}

No external funding was secured for this study.

Availability of data and materials

All of the data supporting our findings is contained within the manuscript.

\section{Authors' contributions}

Patient's treatments and sampling were carried out by Drs. HM, FH, KK, and TY. Drs. HU and TH are pediatric cardiologist, who supported treatment of myocarditis in this patient. Biomarkers analysis was carried out by Dr. HM and TY. Real-time RT-PCR for RSV genome was performed by Dr. MS. Dr. HM drafted the initial manuscript, and Prof. TY reviewed and revised the manuscript. All authors approved the final manuscript as submitted and agree to be accountable for all aspects of the work. 


\section{Authors' information}

Not applicable.

\section{Ethics approval and consent to participate}

Not applicable.

\section{Consent for publication}

Written informed consent was obtained from parents of the patient for publication of this case report. A copy of the written consent is available for review by the Editor of this Journal.

\section{Competing interests}

The authors declare that they have no competing interests.

\section{Publisher's Note}

Springer Nature remains neutral with regard to jurisdictional claims in published maps and institutional affiliations.

\section{Author details}

${ }^{1}$ Department of Pediatrics, Fujita Health University School of Medicine, 1-98, Dengakugakubo, Kutsukake-cho, Toyoake, Aichi 470-1192, Japan. ${ }^{2}$ Graduate School of Health Sciences, Fujita Health University, Toyoake, Aichi, Japan. ${ }^{3}$ Department of Pediatrics, School of Medicine, Fukushima Medical University, Fukushima, Japan.

Received: 20 January 2017 Accepted: 29 January 2018

Published online: 12 February 2018

\section{References}

1. Hakim H, Dallas R, Zhou Y, Pei D, Cheng C, Flynn PM, Pui CH, Jeha S. Acute respiratory infections in children and adolescents with acute lymphoblastic leukemia. Cancer. 2016;122(5):798-805.

2. Hu A, Colella M, Tam JS, Rappaport R, Cheng SM. Simultaneous detection, subgrouping, and quantitation of respiratory syncytial virus a and B by realtime PCR. J Clin Microbiol. 2003;41(1):149-54.

3. El Saleeby CM, Somes GW, DeVincenzo JP, Gaur AH. Risk factors for severe respiratory syncytial virus disease in children with cancer: the importance of lymphopenia and young age. Pediatrics. 2008;121(2):235-43.

4. Chu HY, Chin J, Pollard J, Zerr DM, Englund JA. Clinical outcomes in outpatient respiratory syncytial virus infection in immunocompromised children. Influenza Other Respir Viruses. 2016;10(3):205-10.

5. Armstrong DS, Menahem S. Cardiac arrhythmias as a manifestation of acquired heart disease in association with paediatric respiratory syncitial virus infection. J Paediatr Child Health. 1993;29(4):309-11.

6. Bowles NE, Ni J, Kearney DL, Pauschinger M, Schultheiss HP, McCarthy R, Hare J, Bricker JT, Bowles KR, Towbin JA. Detection of viruses in myocardial tissues by polymerase chain reaction. Evidence of adenovirus as a common cause of myocarditis in children and adults. J Am Coll Cardiol. 2003;42(3):466-72.

7. Menahem S. Respiratory syncytial virus and complete heart block in a child. Cardiol Young. 2010;20(1):103-4.

8. Renko M, Leskinen M, Kontiokari T, Tapiainen T, Hedberg P, Uhari M. Cardiac troponin-I as a screening tool for myocarditis in children hospitalized for viral infection. Acta Paediatr (Oslo, Norway : 1992). 2010;99(2):283-5.

9. Menchise A. Myocarditis in the setting of RSV bronchiolitis. Fetal Pediatr Pathol. 2011;30(1):64-8.

10. Campbell AP, Chien JW, Kuypers J, Englund JA, Wald A, Guthrie KA, Corey L Boeckh M. Respiratory virus pneumonia after hematopoietic cell transplantation $(\mathrm{HCT})$ : associations between viral load in bronchoalveolar lavage samples, viral RNA detection in serum samples, and clinical outcomes of HCT. J Infect Dis. 2010; 201(9):1404-13.

11. Seko Y, Takahashi N, Azuma M, Yagita H, Okumura K, Yazaki Y. Effects of in vivo administration of anti-B7-1/B7-2 monoclonal antibodies on murine acute myocarditis caused by coxsackievirus B3. Circ Res. 1998;82(5):613-8.

12. Huber SA, Feldman AM, Sartini D. Coxsackievirus B3 induces T regulatory cells, which inhibit cardiomyopathy in tumor necrosis factor-alpha transgenic mice. Circ Res. 2006;99(10):1109-16.
13. Yue Y, Gui J, Ai W, Xu W, Xiong S. Direct gene transfer with IP-10 mutant ameliorates mouse CVB3-induced myocarditis by blunting Th1 immune responses. PLoS One. 2011;6(3):e18186.

14. Yue Y, Gui J, Xu W, Xiong S. Gene therapy with CCL2 (MCP-1) mutant protects CVB3-induced myocarditis by compromising Th1 polarization. Mol Immunol. 2011:48(4):706-13.

\section{Submit your next manuscript to BioMed Central and we will help you at every step:}

- We accept pre-submission inquiries

- Our selector tool helps you to find the most relevant journal

- We provide round the clock customer support

- Convenient online submission

- Thorough peer review

- Inclusion in PubMed and all major indexing services

- Maximum visibility for your research

Submit your manuscript at www.biomedcentral.com/submit 